\title{
Estrutura paisagística de São Joãa da Ponta, nordeste do Pará
}

\section{Landscaping structure of São Joãa da Ponta, northeast of Pará}

\author{
Carmena Ferreira de França* \\ Marcia Aparecida da Silva Pimentel** \\ Silvia Caroline Ribeiro Neves***
}

\section{Resumo:}

A posição geográfica de São João da Ponta, no Litoral de Rias do Pará, confere a este município uma estrutura paisagística diversificada em decorrência tanto da influência continental quanto das características costeiras. Este artigo apresenta o mosaico paisagístico do município, com base na análise integrada e sistêmica dos arranjos espaciais formados pelos elementos físicos, biológicos e antrópicos. Foram classificados três geossistemas, doze geofácies e onze geótopos. Estas unidades de paisagem integram uma estrutura hierárquica de grandezas 4, 5 e 6. Este trabalho contribui para os estudos da paisagem, no âmbito da Geografia Física, e resulta de uma aplicação metodológica dos pressupostos de Bertrand (1971).
* Doutora em Geologia e Geoquímica pela Universidade Federal do Pará (UFPA). Professora adjunta no Departamento de Geografia da UFPA.

* Doutora em Geografia Física pela Universidade de São Paulo (USP). Professora associada no Departamento de Geografia da UFPA.

*** Graduanda em Geografia na UFPA.

\begin{abstract}
:
São João da Ponta geographic position, at the coast of Rias do Pará, gives this city a diverse landscaping structure as result of both the continental influence and coastal features. This paper show the landscape mosaic based on the integrated and systematic analysis of the spatial arrangements formed by physical, biological and man-made elements, three geosystems, twelve geofacies and eleven geotopes are labeled. These landscape units are part of a hierarchical structure with quantities 4,5 and 6. This paper contributes to the studies of landscaping, in the context of Physical Geography, and as a result from a methodological application of Bertrand assumptions (1971).
\end{abstract}

Palavras-chave:

geossistema, zona costeira, vegetação, Geografia Física.

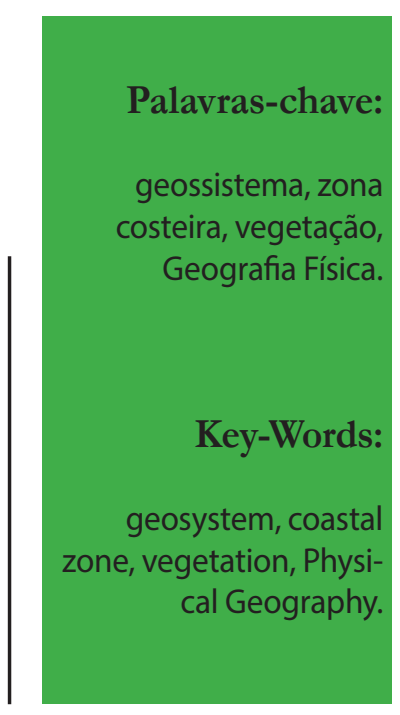


INTRODUÇÃO

município de São João da Ponta localiza-
se na Mesorregião do Nordeste Paraense e na Microrregião do Salgado (IBGE, 1990). Foi criado a partir do desmembramento da porção sudeste do município de São Caetano de Odivelas, conforme a Lei Estadual n. ${ }^{\circ}$ 5.920, de 27 de dezembro de 1995. Este fato justifica sua posição geográfica na retroterra da Microrregião do Salgado, limitando-se com Curuçá, a leste e a norte, com São Caetano de Odivelas a oeste e com Terra Alta ao sul.

Do ponto de vista físico, o município insere-se no Planalto Rebaixado da Bragantina e no Litoral de Rias do Pará (BARBOSA; PINTO, 1973). Mais especificamente, situa-se numa porção recuada e interna da costa paraense, entre dois grandes estuários, o Mojuim e o Mocajuba, que delimitam o município a oeste e a leste, respectivamente. Esta posição geográfica confere a São João da Ponta características naturais operadas tanto por fatores continentais, quanto flúvio-marinhos.

Soma-se a isso, a relativa proximidade com a capital paraense (dista, aproximadamente, $120 \mathrm{~km}$ de Belém) e a integração com outros municípios da região, através da rede viária federal e estadual (BR316, PA-136, PA-375 e PA-238) e das estradas vicinais.

As peculiaridades naturais, traduzidas pelas formas de relevo, coberturas sedimentares superficiais, hidrodinâmica e vegetação, definem um arcabouço geomorfológico e biótico que promove e justifica o uso da terra. Este é representado pelas atividades sócio-econômicas e pelas formas de ocupação territorial, principalmente extrativistas, sustentadas pelas bases físicas e logísticas. A interação de todos esses fatores (físicos, biológicos e antrópicos) confere, a São João da Ponta, uma estrutura espacial diversificada, requerendo, para a sua análise, a visão sistêmica e o conceito de paisagem.

Os estudos da paisagem, no âmbito da Geografia Física, privilegiam a análise integrada e sistêmica dos arranjos espaciais formados pelos elementos físicos, biológicos e antrópicos. A combinação desses fatores determina a organização de conjuntos paisagísticos, que se diferenciam pela distribuição espacial, frequência e intensidade de manifestação de seus componentes ou fenômenos
(BERTRAND, 1971; RODRIGUEZ et al., 2010).

A paisagem foi concebida, neste trabalho, como um sistema constituído por elementos que podem ser subdivididos em físicos, biológicos e antrópicos. Tais componentes se combinam de modo particular e diversificado, dando origem a conjuntos paisagísticos. Não se trata da simples associação ou somatória de elementos, mas da relação e da interação que definem a paisagem como totalidade, dando-lhe consistência, indissociabilidade e materialidade. Ela é, portanto, uma parte do espaço geográfico, caracterizada por determinada combinação de elementos do meio físico, como o relevo, o clima, as rochas e as águas, do meio biológico representado, sobretudo, pela vegetação e pelo solo, da ação antrópica expressa através das formas de uso e ocupação dos demais elementos da paisagem (BERTRAND, 1971).

Para o reconhecimento ou identificação das diferentes unidades de paisagem, é necessário o levantamento de dados de campo para a elaboração de um inventário, a ser complementado por informações decorrentes da interpretação de bases cartográficas, mapas temáticos e produtos de sensores remotos.As medidas relativas à morfometria do relevo a partir do levantamento topográfico, a caracterização da estrutura da vegetação articulada com a identificação da composição florística, bem como a classificação das diferentes formas de uso da terra estão entre os procedimentos mais utilizados pela ciência da paisagem. Tal roteiro metodológico foi empregado no município de São João da Ponta, com a finalidade de analisar a estrutura espacial variada, mapear e caracterizar as unidades paisagísticas. Isso revelou o mosaico de unidades espaciais presente na área de estudo, as relações entre seus componentes mesológicos e permitiu a compreensão da organização interna de cada unidade.

O presente estudo buscou classificar as unidades de paisagem do município de São João da Ponta em geossistemas, geofácies e geótopos, bem como descrever tais unidades a partir de uma concepção integrada dos elementos do meio físico, biológico e antrópico. Este trabalho resultou de uma aplicação metodológica dos pressupostos de Bertrand (1971), contribuindo para os estudos da paisagem, no âmbito da Geografia Física. 


\section{MATERIAL E MÉTODOS}

Os procedimentos metodológicos para a elaboração deste artigo foram executados em 4 etapas: (1) revisão dos fundamentos teóricos da Geografia Física Global para definição do conceito de paisagem e adequação metodológica à realidade costeira de São João da Ponta, utilizando-se a concepção sistêmica e integrada para analise da paisagem proposta por Bertrand (1971); (2) trabalho de campo para levantamento topográfico expedito, tipologia de atividades humanas, descrição de elementos fisionômicos da vegetação (formas biológicas, tamanho, estratificação e grau de cobertura do solo), identificação de gêneros florísticos e registros fotográficos; (3) processamento digital e interpretação de imagens da Missão Topográfica Radar Shuttle (SRTM), com resolução espacial de $90 \mathrm{~m}$ por pixel (cenas SA-23-V-A e SA-22-X-B disponíveis em http:// www.relevobr.cnpm.embrapa.br/download/pa/ pa.htm), através do Programa Quantum Gis 2.6; (4) confecção do mapa topográfico de São João da Ponta, elaboração de perfis topográficos, cruzamento dos dados topográficos com informações de campo para a compartimentação morfológica do município e confecção dos mapas de unidades de paisagem.
2. COMPARTIMENTAÇÃO MORFOLÓGICA, COBERTURA VEGETAL Ẻ ESTRUTURA DA PÁISAGEM DE SÃO JOÃO DA PONTA

A localização geográfica do município de São João da Ponta proporciona duas características importantes do ponto de vista das grandes divisões do relevo. A primeira é a sua inserção em dois compartimentos morfoestruturais: o Planalto Rebaixado da Bragantina e o Litoral de Rias do Pará (BARBOSA; PINTO, 1973); e a segunda é a distribuição espacial da planície costeira em faixas alongadas e marginais aos grandes estuários Mojuim e Mocajuba.

O Planalto Rebaixado da Bragantina é uma unidade de expressão regional e ocupa cerca de $80 \%$ do território municipal. Em função disso, a morfologia é marcada pela superfície aplainada dos baixos platôs e tabuleiros, além de colinas. Predominam formas de denudação de topo tabular a ligeiramente convexo e vertentes planas a suavemente convexizadas.

De acordo com a análise morfométrica, os vales são geralmente assimétricos e alargados, apresentam dimensão interfluvial, em média, superior a 2.500 metros. São pouco aprofundados com entalhamento de drenagem entre 6 e 9 metros, e vertentes com gradiente igual ou inferior a $1^{\circ} 30^{\prime}$. Isso caracteriza um índice de dissecação muito baixo para o município (Figura 1).

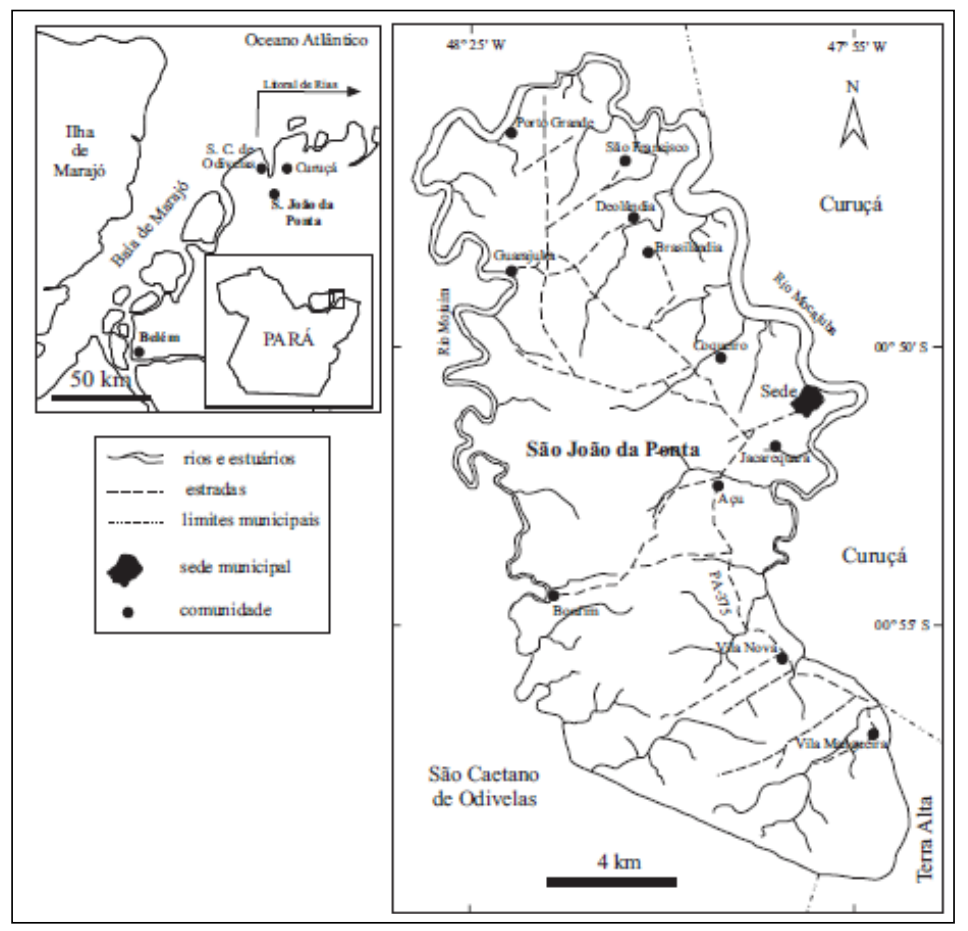

Figura 1: Localização de São João da Ponta, Pará.

Fonte: elaborado pelas autoras. 
As maiores cotas topográficas estão entre 10 e 25 metros. Concentram-se na parte sul do município e ao longo de um eixo com orientação preferencial norte-sul, que representa o principal divisor entre as bacias hidrográficas do Mojuim e do Mocajuba. Desse modo, os setores elevados topograficamente demarcam a posição das cabeceiras fluviais. A maioria dos rios tem suas nascentes na porção central do município e vertem para o leste e para o oeste, onde deságuam nos dois principais estuários. Esta distribuição topográfica influencia no arranjo da rede de drenagem sob o padrão radial centrífugo. A rede hidrográfica é constituída de canais de baixa hierarquia, que vertem para os rios Mojuim e Mocajuba. São rios de pequena extensão e caudal se comparados aos dois rios principais. Trata-se de igarapés de águas claras que têm suas nascentes nas veredas de buritizais e açaizais, e de matas alagadas alojadas nos fundos de vale. Os igarapés de água clara são comuns em decorrência dos fatores físicos preponderantes no município. Estes canais drenam áreas de latossolo amarelo areno-argiloso dos baixos platôs e tabuleiros, com cobertura de capoeiras. Em razão disso, transportam muita carga de fundo e pouca matéria em suspensão (SIOLI, 1990).

O Litoral de Rias é um macrocompartimento costeiro do Nordeste Paraense, no qual se inserem as porções norte, leste e oeste de São João da Ponta, enquadrada pelos estuários supracitados. Nestes setores do município, é expressivo o número de ilhas, furos e planícies submetidas à ação das marés, que alcançam amplitudes de até 5 metros (regime de macromarés) (MARINHA DO BRASIL, 2015). Estas têm efeito dominante em função do gradiente topográfico mais suave. Além disso, as marés influenciam o baixo curso dos igarapés afluentes do Mojuim e do Mocajuba. A penetração da maré, durante o fluxo, modifica o regime e a direção da corrente fluvial, de modo que esses cursos são controlados mais pela hidrodinâmica estuarina do que pela variação sazonal da pluviosidade.

A outra característica geomorfológica relevante, decorrente da posição recuada de São João da Ponta e da sua inserção no Litoral de Rias é a distribuição espacial da planície costeira em faixas alongadas e longitudinais aos grandes estuários e aos baixos cursos dos igarapés tributários. A planície costeira é constituída, predominantemente, de planícies de maré lamosas revestidas por mangues, com limites internos estabelecidos nos rebordos dos baixos platôs que integram o Planalto Rebaixado da Bragantina.

O contato dos platôs com as planícies de maré caracteriza-se por forte diferença topográfica e vegetacional. No que se refere ao aspecto topográfico, este limite é marcado por borda abrupta e erosiva, do tipo falésia ativa, com alturas entre 0,5 e 2,0 metros, impondo gradientes de $3^{\circ}$ a $17^{\circ}$, entre o rebordo do platô e a planície de maré (Figura 2). Sob a perspectiva de uma visão em planta, a borda descreve uma forma denteada e irregular, marcada pela presença de pequenos anfiteatros erosivos. Tais características enfatizam o controle por dois fatores de ordem morfogenética, que atuam em escalas diversas de espaço e tempo: a neotectônica e a dinâmica estuarina. A influência da neotectônica é evidenciada pelo rebordo elevado e escarpado que delimita o contato platô

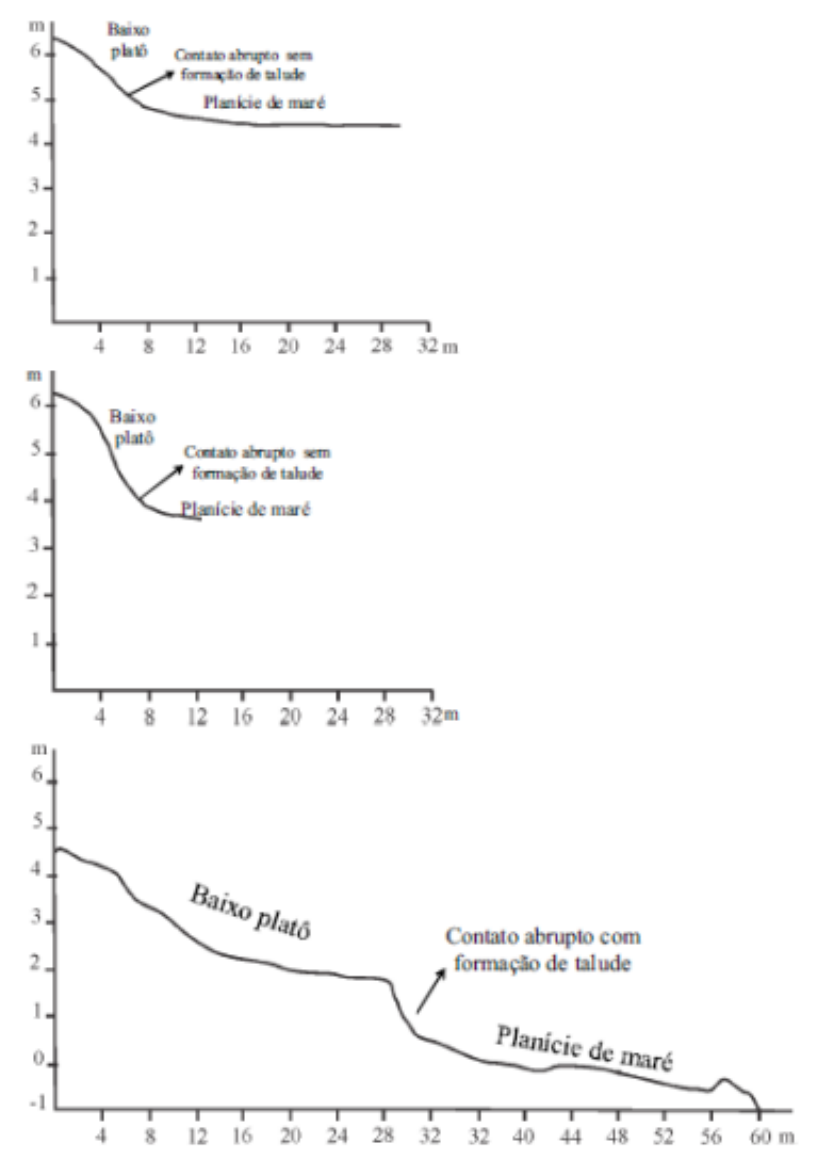

Figura 2: Perfis topográficos nas zonas de contato entre o baixo platô e a planície de maré, mostrando o limite demarcado ou não pela presença de talude erosivo. $O$ gradiente é de $3^{\circ}, 5^{\circ}$ e $12^{\circ}$, respectivamente.

Fonte: elaborado pelas autoras. 
-planície. A dinâmica estuarina, representada principalmente pela flutuação semidiurna da macromaré, controla a distribuição espacial da planície revestida por mangue, incluindo a disposição geométrica dos setores fisionômicos vegetacionais, que serão tratados posteriormente neste artigo.

Compreende-se como estrutura paisagística o arranjo espacial determinado pela distribuição das formas de relevo, das cotas topográficas, da cobertura vegetal e dos tipos de uso e ocupação. A estrutura paisagística não é um simples mosaico, mas sim uma organização resultante da interação sistêmica dos diversos fatores geológicos, morfogenéticos, pedogenéticos, vegetacionais e antropogênicos (BERTRAND, 1971; RODRIGUEZ et al., 2010).

A estrutura paisagística não é imutável. Ao contrário, é dinâmica ao longo do tempo. Entendese, portanto, como dinâmica paisagística o conjunto de transformações estruturais que são observadas em escalas temporais de uma ou mais décadas. Essas mudanças são causadas tanto por fatores físicos como antropogênicos. Os fatores morfológicos, morfométricos e hidrodinâmicos destacam-se como os mais importantes condicionantes físicos das mudanças temporais da paisagem. Os agentes hidrodinâmicos são representados pelas marés, pelas correntes e pelo escoamento da água da chuva. Por outro lado, as formas de uso e ocupação da terra, expressas pelas atividades rurais e urbanas, compõem o conjunto de fatores antrópicos responsáveis pela reorganização da estrutura paisagística.

Os setores mais dinâmicos do ponto de vista paisagístico são aqueles influenciados pelo gradiente e pela rede de canais de baixa hierarquia, pela ampli- tude de maré e pelo meandramento dos canais estuarinos do Mojuim e do Mocajuba. As paisagens mais sujeitas ao dinamismo dos elementos físicos são aquelas localizadas na zona de transição entre o baixo platô e a planície costeira, onde o gradiente está entre $3^{\circ}$ a $17^{\circ}$, e nas áreas alagáveis, onde o regime é misto (fluvial e de maré). No primeiro caso, a dinâmica paisagística se manifesta pela frequência das formas erosivas que se desenvolvem nas bordas dos platôs, como falésias, terracetes, marcas de solapamento e de desabamento. Essas formas atestam a ação de processos erosivos patrocinados pelo escoamento superficial da água da chuva, pelas correntes de maré e pelos fluxos de subsuperfície. Estes últimos exercem um papel importante como nascedouros de pequenos canais na base das escarpas. Nestes setores, a borda dos platôs adquire uma geometria irregular, numa perspectiva em planta, pela presença de anfiteatros que, por sua vez, contribuem, devido à sua forma côncava, para a convergência e concentração dos fluxos que se canalizam na direção das planícies de maré (Figura 3).

No segundo caso, nas áreas inundáveis sob regime misto flúvio-marinho, a amplitude de maré, que alcança até 5 metros nas sizígias, é responsável pela alternância de processos deposicionais e erosivos, controlados pela rede de canais de maré, de diferentes dimensões e hierarquia, que desempenham um papel morfodinâmico importante em função das correntes de enchente e vazante que atuam em sentido oposto, bem como em função do transporte de sedimentos (Figura 4).

Ao mesmo tempo que os canais funcionam como vias de penetração da maré e de transporte de sedimentos e nutrientes para o mangue, duran-
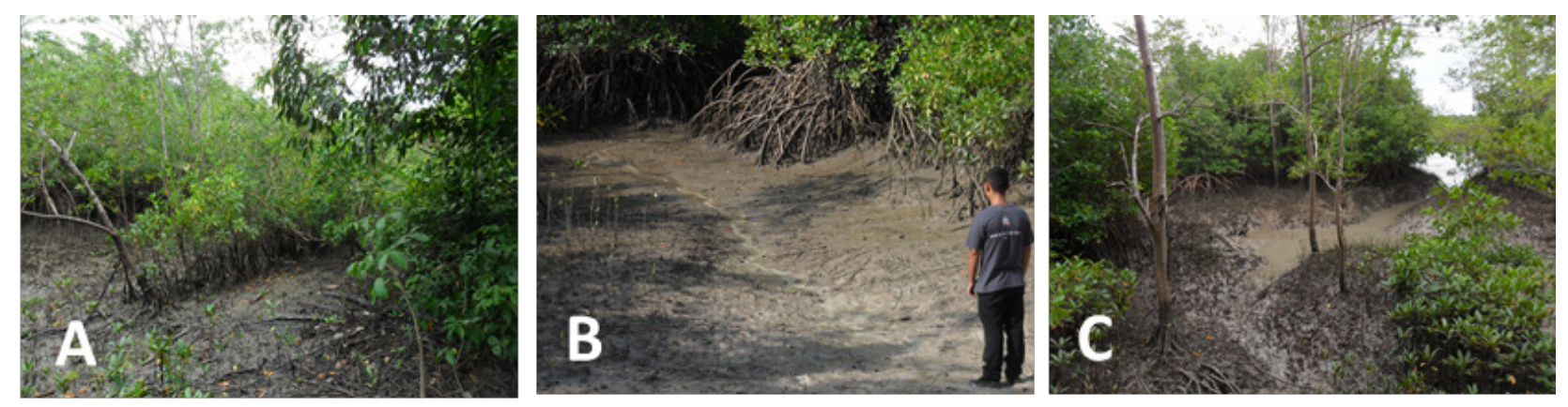

Figura 3: (A) Anfiteatros erosivos na zona de contato entre o platô e a planície de maré; (B) e (C) Canais de baixa hierarquia originados nas base das escarpas e dos anfiteatros e que se direcionam para as planícies de maré, compondo a rede de drenagem dessas áreas alagáveis.

Fonte: acervo das autoras (09/2014). 

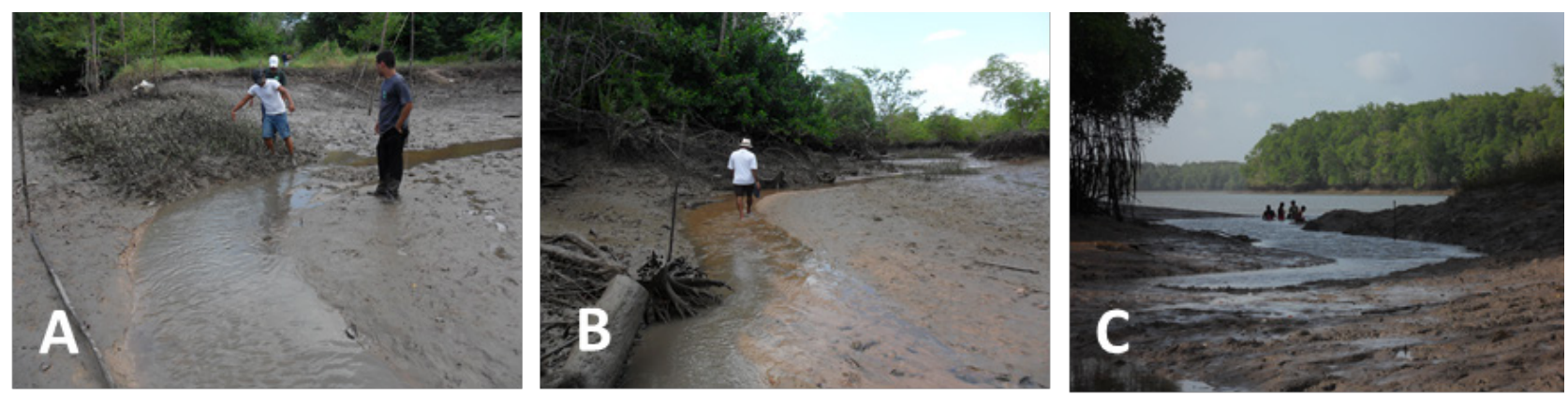

Figura 4: Igarapé do Tapuranga, durante a maré baixa: o leito de inundação exibe uma morfologia variada devido ao gradiente topográfico do canal, à amplitude de maré e à dinâmica sedimentar do leito lamoso.

Fonte: acervo das autoras (09/2014).

te o fluxo, comportam-se, também, como eixos de dissecação das planícies de maré, durante o refluxo, em função do processo de escoamento canalizado e consorciado das águas dos igarapés e das marés. No momento do refluxo, as correntes apresentam maior velocidade de escoamento, proporcionando entalhamento dos talvegues e erosão das superfícies lamosas das planícies inundáveis.

Além dos fatores abióticos, a cobertura vegetal é outro componente fundamental da paisagem. Não se trata apenas de uma cobertura do solo. Ela é concebida, sobretudo, como síntese das múltiplas relações com o meio físico e antrópico, refletindo as condições mesológicas definidas pela topografia e morfologia, pelo substrato, pelas condições de temperatura, umidade e salinidade, pelo solo e pelo uso da terra. A vegetação é um dos elementos estruturadores da paisagem, sendo utilizada para identificar, delimitar e caracterizar unidades paisagísticas, como os geossistemas e os geofácies (BERTRAND, 1971).

Em São João da Ponta, a identificação das diferentes coberturas vegetais foi associada à distribuição das formas de relevo, do gradiente topográfico, da inundação por maré e dos níveis de transformação antrópica. Os principais tipos vegetais são: (1) floresta secundária dos baixos platôs (capoeira e capoeirão) com presença de Simarouba sp. (marupá), Hyeronima sp. (pau ou orelha-de-cotia), Cedrela sp. (cedro), Hevea sp. (seringueira), Platonia sp. (bacurizeiro), Endopleura sp. (uxizeiro), Cecropia sp. (imbaúba) e Vismia sp. (lacre); (2) floresta densa de planície aluvial com presença de Carapa sp. (andirobeira), Virola sp. (ucuúba), Tachigalia sp. (tachi), Symphonia sp. (anani), Euterpe sp. (açaizeiro) e Mauritia sp. (miritizeiro); e (3) bosque de mangue das planícies de maré, com presença predominante de Rhyzophora sp. (mangueiro), Avicennia sp. (siriubeira), Laguncularia sp. (tinteira) e Acrostichum sp. (samambaia do mangue).

A planície de maré exibe quatro setores distintos de mangue. No 1..$^{\circ}$ setor, localizado nos 100 primeiros metros da planície, demarcados a partir do limite com o platô, a vegetação de mangue é constituída de plântulas e indivíduos herbáceos. O substrato é influenciado por sedimentos arenosos provenientes do platô por escoamento superficial da água da chuva. São comuns os gêneros Laguncularia sp.e Acrostichum sp. O 2. ${ }^{\circ}$ setor, situado após esta 1. a zona, é caracterizado por mangue jovem com predomínio dos gêneros Avicennia sp. e $R y$ zophora sp.. O 3..$^{\circ}$ setor é composto por bosque adulto, mas de estrato arbóreo baixo (menos de 10 metros de altura) e raras plântulas. $O$ substrato é menos influenciado pelos sedimentos do platô. Porém, os afloramentos de arenito ferruginoso indicam, não apenas a proximidade com o planalto, mas também a presença de leito rochoso mais antigo (Plioceno-Pleistoceno), que serve de embasamento para os depósitos síltico -argilosos. Por fim, o 4..$^{\circ}$ setor corresponde ao bosque de árvores adultas do gênero Ryzophora sp., com altura média e alta (entre 10 e 25 metros e acima de 25 metros), situado na porção externa da planície, cujas cotas topográficas variam entre 0 e 5 metros (faixa de intermarés) e onde o substrato é síltico-argiloso.

\section{UNIDADES DE PAISAGEM DE SÃO JOÃO DA PONTA, PARÁ}

De acordo com Bertrand (1971), a paisagem deve ser investigada com base na concepção de totalidade e no encadeamento de unidades em níveis de 
grandeza espaço-temporais. A totalidade significa a indissociabilidade entre os componentes paisagísticos, que se articulam dialeticamente, definindo conjuntos que expressam a mesma dinâmica e evolução. A classificação das unidades em níveis de grandeza resulta numa hierarquia taxonômica de acordo com a escala espacial de análise e com a escala cartográfica de representação. Para o autor supracitado, há seis níveis têmporo-espaciais, desde o mais abrangente espacialmente até o mais localizado: zona, domínio, região, geossistema, geofácies e geótopo.

Esta base teórica, aplicada ao município de São João da Ponta, permite a identificação de conjuntos paisagísticos em três ordens de grandeza: geossistema, geofácies e geótopo (4. ${ }^{\mathrm{a}}, 5$. $^{\mathrm{a}}$ e 6 . $^{\mathrm{a}}$ grandezas), que são apresentados e sintetizados no Quadro 1 e nas Figuras 5 e 6.

As unidades foram classificadas com base

Quadro 1: Geossistemas, geofácies e geótopos (unidades paisagísticas de 4. a , 5. a e 6.a grandezas) do município de São João da Ponta.

\begin{tabular}{|c|c|c|c|c|c|}
\hline \multicolumn{4}{|c|}{ UNIDADES DE 4 . $^{\mathrm{a}}$ GRANDEZA } & \multirow{2}{*}{$\begin{array}{l}\text { UNIDADES DE 5. } \\
\text { GRANDEZA } \\
\text { GEOFÁCIES }\end{array}$} & \multirow{2}{*}{$\begin{array}{c}\text { UNIDADES DE } 6 .^{\text {a }} \\
\text { GRANDEZA } \\
\text { GEÓTOPOS }\end{array}$} \\
\hline GEOSSISTEMAS & $\begin{array}{l}\text { Potencial } \\
\text { ecológico }\end{array}$ & $\begin{array}{c}\text { Exploração } \\
\text { biológica }\end{array}$ & $\begin{array}{c}\text { Ação } \\
\text { antrópica }\end{array}$ & & \\
\hline $\begin{array}{c}\text { Capoeiras e } \\
\text { capoeirões sobre } \\
\text { baixos platôs, } \\
\text { tabuleiros e colinas } \\
\text { degradados com } \\
\text { dinâmica } \\
\text { progressiva e } \\
\text { regressiva sob forte } \\
\text { antropismo devido } \\
\text { ao uso urbano e } \\
\text { rural }(\mathrm{Gl})\end{array}$ & $\begin{array}{l}\text { Planaltos de topo } \\
\text { tabular e colinas } \\
\text { semi-convexizadas, } \\
\text { cotas entre } 5 \text { e } 25 \\
\text { m, coberturas } \\
\text { superficiais areno- } \\
\text { argilosas da } \\
\text { Formação } \\
\text { Barreiras/Pós- } \\
\text { Barreiras }\end{array}$ & $\begin{array}{c}\text { Capoeiras em } \\
\text { diferentes estágios } \\
\text { de desenvolvimento } \\
\text { e densidade, solos } \\
\text { bem drenados do } \\
\text { tipo latossolo } \\
\text { amarelo arenoso ou } \\
\text { areno-argiloso }\end{array}$ & $\begin{array}{l}\text { Extrativismo } \\
\text { vegetal, } \\
\text { roçados e } \\
\text { pequenas } \\
\text { atividades } \\
\text { criatórias } \\
\text { Uso urbano }\end{array}$ & $\begin{array}{c}\text { Talude ou falésia } \\
\text { sedimentar sob ação } \\
\text { erosiva flúvio-marinha } \\
\text { Superfície cultivada com } \\
\text { pasto } \\
\text { Superfície desmatada } \\
\text { pelo extrativismo mineral } \\
\text { Superfície em } \\
\text { regeneração florestal com } \\
\text { Simarouba sp., Hevea } \\
\text { sp., Platonia sp., } \\
\text { Endopleura sp., Cecropia } \\
\text { sp. e Vismia sp. } \\
\text { Superfície construída } \\
\text { para fins urbanos }\end{array}$ & $\begin{array}{c}\text { Terracetes } \\
\text { Marcas de } \\
\text { solapamento e de } \\
\text { desabamento } \\
\text { Anfiteatros erosivos } \\
\text { Ravinas, sulcos e } \\
\text { filetes gerados pelo } \\
\text { escoamento pluvial } \\
\text { canalizado } \\
\text { Canaletas de } \\
\text { escoamento hídrico } \\
\text { residual }\end{array}$ \\
\hline $\begin{array}{c}\text { Formações } \\
\text { florestais alagáveis } \\
\text { das planícies } \\
\text { aluviais, com } \\
\text { dinâmica } \\
\text { progressiva pelo } \\
\text { uso extrativista e } \\
\text { urbano (GII) }\end{array}$ & $\begin{array}{c}\text { Planícies de } \\
\text { inundação em } \\
\text { fundos de vale } \\
\text { pouco } \\
\text { aprofundados por } \\
\text { igarapés de água } \\
\text { clara com regime } \\
\text { controlado pela } \\
\text { sazonalidade } \\
\text { pluviométrica, cotas } \\
\text { entre } 0 \text { e } 5 \text { m, } \\
\text { coberturas } \\
\text { arenosas ou } \\
\text { argilosas }\end{array}$ & $\begin{array}{l}\text { Florestas aluviais e } \\
\text { veredas de } \\
\text { buritizais, solos } \\
\text { arenosos e } \\
\text { argilosos } \\
\text { hidromórficos }\end{array}$ & $\begin{array}{l}\text { Extrativismo } \\
\text { vegetal e } \\
\text { animal }\end{array}$ & $\begin{array}{c}\text { Planície aluvial com } \\
\text { Euterpe sp. } \\
\text { Planície aluvial com } \\
\text { Mauritia sp. } \\
\text { Planície aluvial com mata } \\
\text { degradada por } \\
\text { alagamento prolongado } \\
\text { ou por represamento }\end{array}$ & $\begin{array}{l}\text { Canal assoreado } \\
\text { por depósito de } \\
\text { cascalho } \\
\text { Canal assoreado } \\
\text { por depósito } \\
\text { arenoso } \\
\text { Superfície lodosa } \\
\text { por acúmulo de } \\
\text { matéria orgânica } \\
\text { vegetal } \\
\text { Superfície aterrada } \\
\text { e construída para } \\
\text { lazer, circulação ou } \\
\text { moradia }\end{array}$ \\
\hline $\begin{array}{c}\text { Formações } \\
\text { florestais halófitas } \\
\text { flúvio-marinhas em } \\
\text { planícies de maré } \\
\text { lamosas, com } \\
\text { estabilidade } \\
\text { dinâmica ou } \\
\text { climácica sob uso } \\
\text { extrativista (GIII) }\end{array}$ & $\begin{array}{l}\text { Planícies de maré, } \\
\text { cotas de } 0 \text { a } 5 \mathrm{~m} \text {, } \\
\text { coberturas } \\
\text { sedimentares } \\
\text { siltosas e } \\
\text { argilosas, } \\
\text { hidrodinâmica } \\
\text { definida por } \\
\text { macromarés de } 5 \mathrm{~m} \\
\text { de amplitude, } \\
\text { durante as sizígias }\end{array}$ & $\begin{array}{l}\text { Mangue adulto e } \\
\text { senil; solos } \\
\text { hidromórficos } \\
\text { indiscriminados de } \\
\text { mangue }\end{array}$ & $\begin{array}{c}\text { Extrativismo } \\
\text { vegetal e } \\
\text { animal }\end{array}$ & $\begin{array}{c}\text { Planície de supramaré } \\
\text { arenosa com plântulas de } \\
\text { Laguncularia sp. e } \\
\text { Acrostichum sp. } \\
\text { Planície de intermaré } \\
\text { areno-lamosa com jovens } \\
\text { Ryzophora sp. e } \\
\text { Avicennia sp. } \\
\text { Planície de intermaré } \\
\text { lamosa e cascalhosa com } \\
\text { estrato baixo de } \\
\text { Ryzophora sp. } \\
\text { Planície de intermaré } \\
\text { lamosa com Ryzophora } \\
\text { sp. }\end{array}$ & $\begin{array}{c}\text { Barras flúvio- } \\
\text { marinhas síltico- } \\
\text { argilosas } \\
\text { colonizadas por } \\
\text { plântulas de } \\
\text { Avicennia sp. e } \\
\text { Ryzophora sp. } \\
\text { Reentrâncias } \\
\text { erosivas } \\
\text { associadas a } \\
\text { atracadouros e/ou } \\
\text { exutório de } \\
\text { drenagens de baixa } \\
\text { hierarquia } \\
\text { colonizados por } \\
\text { Ryzophora sp. }\end{array}$ \\
\hline
\end{tabular}

Fonte: elaborado pelas autoras. 


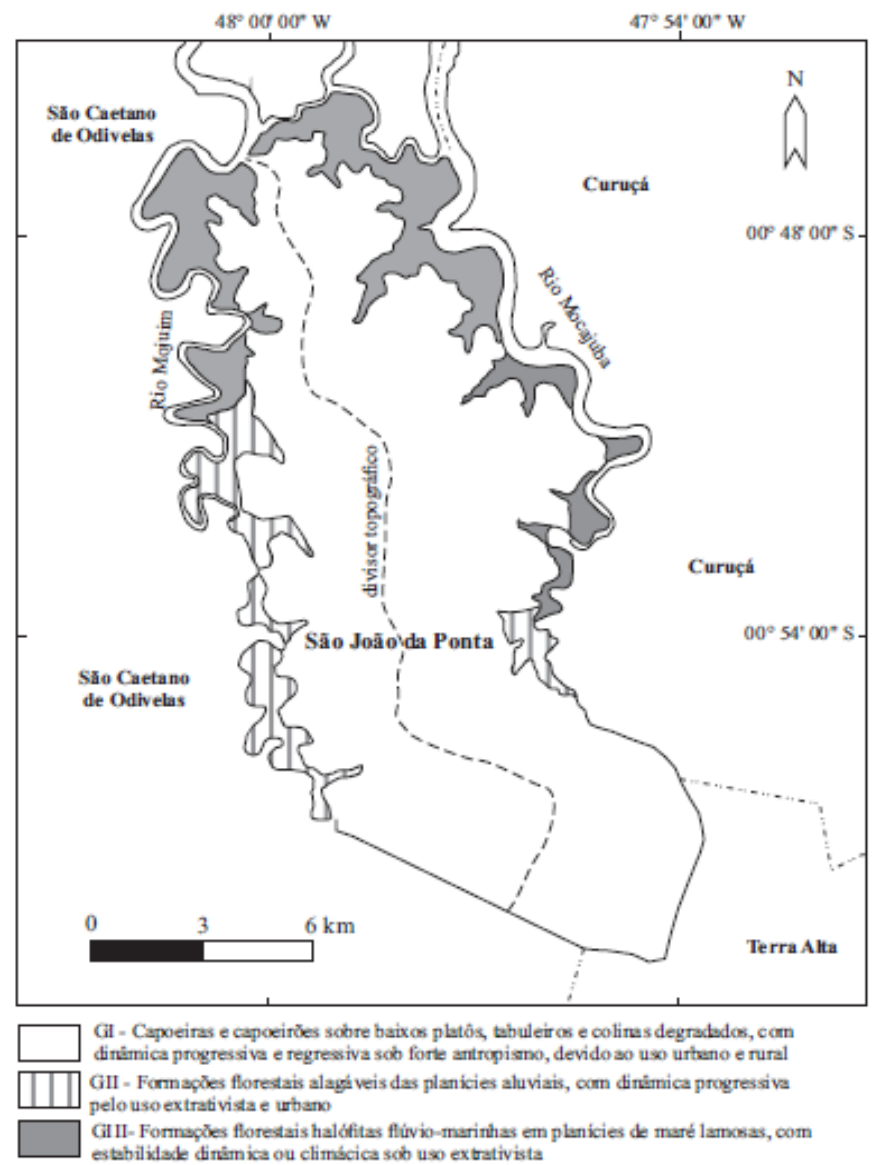

Figura 5: Unidades paisagísticas de $4 .^{\text {a }}$ grandeza (geossistemas) de São João da Ponta Fonte: elaborado pelas autoras.

em dois critérios: fisionômico-ecológico e dinâmico. De acordo com a tipologia fisionômico-ecológica, as paisagens são identificadas e nomeadas pela cobertura vegetal e pela composição florística relacionada com o relevo, a litologia, a hidrodinâmica e o uso da terra. Quanto aos critérios dinâmicos, considera-se o estado de estabilidade ou instabilidade do meio físico, determinado por processos geomorfológicos (modificação ou não do potencial ecológico), e o estágio de desenvolvimento ou o nível de degradação da vegetação e dos solos por forças naturais ou pela ação humana (BERTRAND, 1971).

A estrutura paisagística do Gl (geossistema das capoeiras e capoeirões sobre baixos platôs, tabuleiros e colinas degradados com dinâmica progressiva e regressiva sob forte antropismo devido ao uso urbano e rural), conforme os critérios fisionômicos e ecológicos, é constituída por baixos planaltos de superfície tabular ou suavemente ondulada e por colinas semi- convexizadas, cujas cotas topográficas estão entre 5 e 25 metros. A morfogênese elaborou-se em duas fases, sendo a primeira mais antiga e determinada pelos processos de pediplanação sob clima mais seco, durante o Pleistoceno. A segunda é controlada pelo clima úmido atual e pela atividade fluvial dos canais de baixa hierarquia. Predominam os argilitos e arenitos da Formação Barreiras e as coberturas areno-argilosas dos Sedimentos Pós-Barreiras, sobre os quais se desenvolvem os latossolos amarelos.

A combinação de fatores topográficos, morfológicos, hídrológicos e edáficos favoreceu a expansão, durante o Holoceno, da floresta ombrófila densa. Entretanto, a ocupação por atividades agropecuárias e urbanas, que se intensificaram a partir da década de 1990, modificaram a exploração biológica, particularmente no que se refere à cobertura vegetal. Devido à ação antrópica, a floresta ombrófila foi substituída por pastagens e culturas, ou desmatada para a extração de recursos minerais, para a 


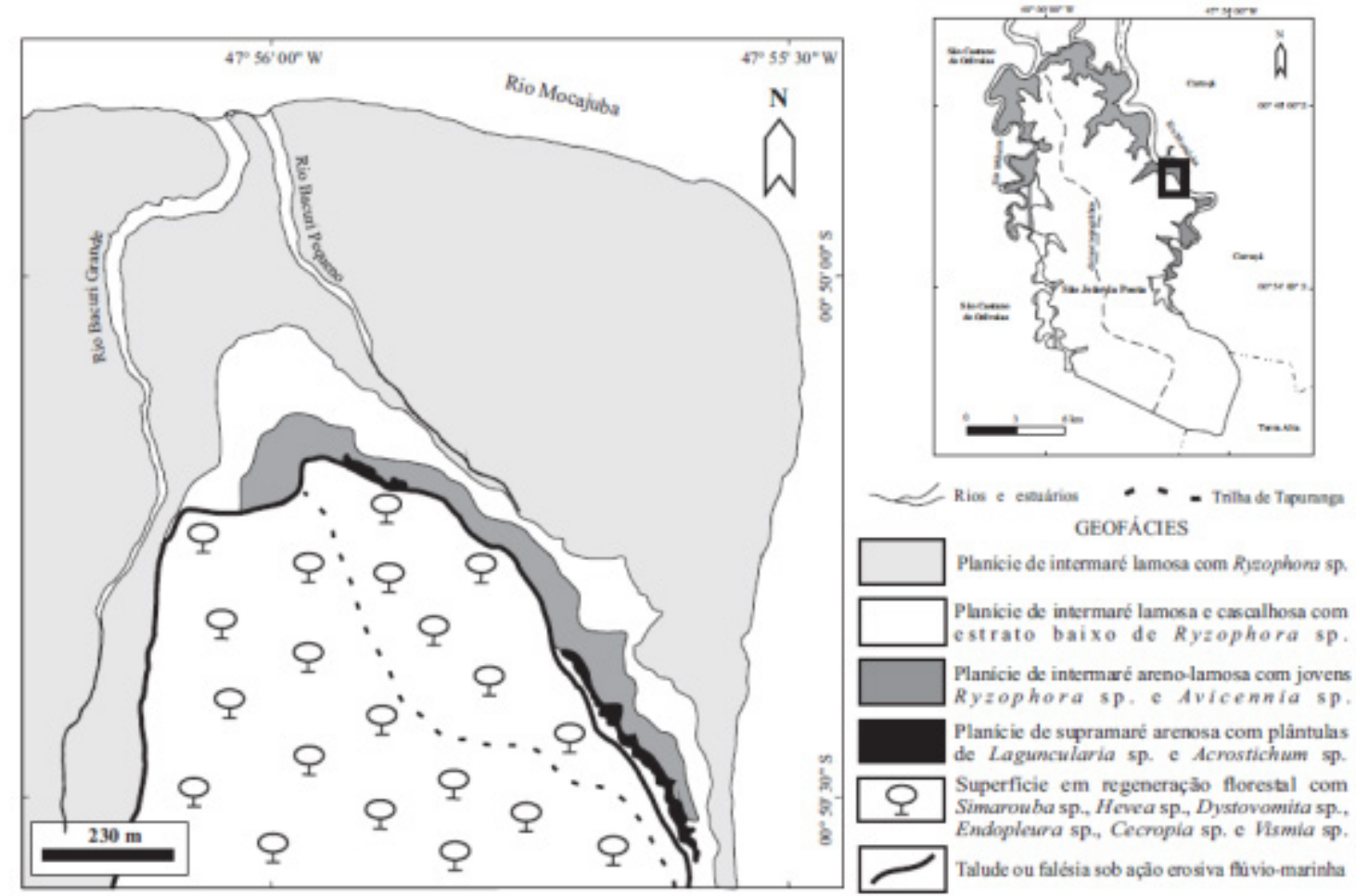

Figura 6: Unidades paisagísticas de 5. a grandeza (geofácies) de um setor da porção leste de São João da Ponta. Fonte: elaborado pelas autoras.

construção de estradas e áreas urbanas. Os pastos e cultivos abandonados, bem como as quadras urbanas não construídas, foram colonizados por vegetação secundária, constituída por capoeiras em diferentes estágios de desenvolvimento e densidade, que se adaptaram aos solos arenosos ou areno-argilosos bem drenados (latossolos). Atualmente, as formas de uso e ocupação antrópica estão ligadas às atividades urbanas da sede municipal e das comunidades locais, à implantação de roças e roçados e às pequenas atividades de pecuária.

Ao longo de décadas de ocupação, a cobertura vegetal original e os canais de drenagem de baixa hierarquia degradaram-se em função do antropismo. Embora o potencial ecológico (formas de relevo e coberturas sedimentares superficiais) não apresente mudança significativa, o mesmo não acontece com a vegetação. Em alguns setores, há reconstituição de uma cobertura florestal, porém diferente da original, chamada de capoeira densa ou capoeirão (IBGE, 1991), o que caracteriza uma dinâmica paisagística progressiva. Em outros setores, a reconstituição florestal é difícil, mantendo-se a cobertura de capoeira baixa ou aberta, o cultivo de roças e roçados, as pastagens e as áreas desmatadas. Neste caso, a dinâmica paisagística é regressiva.

Em função da atividade erosiva que ocorre no rebordo dos planaltos tabulares, promovida pelas correntes de maré dos estuários Mojuim e Mocajuba, classificam-se como geofácies os taludes ou falésias sedimentares sob ação erosiva flúvio-marinha. Neste geofácies, são classificados os seguintes geótopos: terracetes, marcas de solapamento e de desabamento e anfiteatros erosivos (Figura 7).

Outras unidades paisagísticas são decorrentes das atividades agrárias, do extrativismo mineral e da implantação de estradas vicinais sem pavimentação asfáltica em áreas planálticas e colinosas. Nesses casos, identificam-se os seguintes geofácies: superfície cultivada com pasto, superfície desmatada pelo extrativismo mineral e superfície construída para fins urbanos. Nestes, estão os geótopos: sulcos e filetes gerados pelo escoamento pluvial canalizado e canaletas de escoamento hídrico residual (Figura 8).

O GII (Geossistema das formações florestais alagáveis das planícies aluviais, com dinâmica progressiva pelo uso extrativista e urbano) tem 

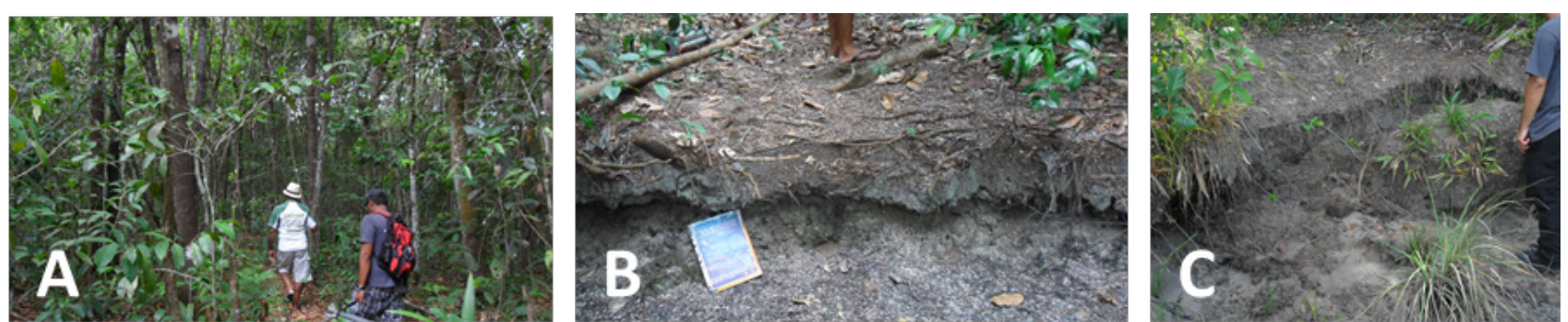

Figura 7: Geofácies e geótopos: (A) Superfície em regeneração florestal com Simarouba sp., Hevea sp., Platonia sp., Endopleura sp., Cecropia sp. e Vismia sp.; (B) terracete; (C) marca de desabamento.

Fonte: acervo das autoras (setembro e outubro de 2014).
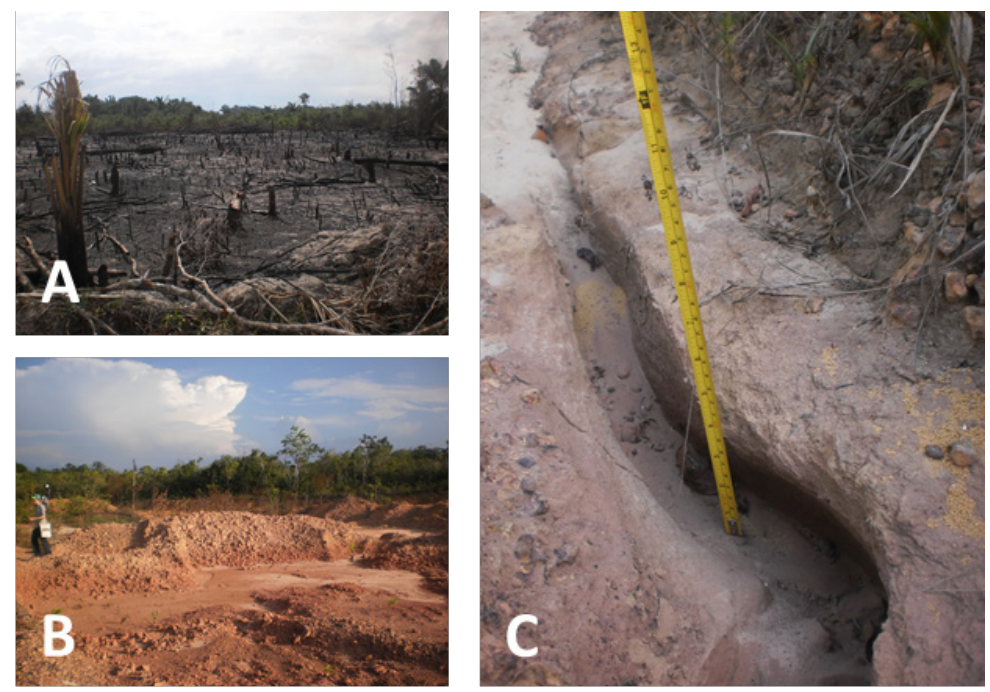

Figura 8: (A) e (B) Superfície desmatada para pasto e extrativismo mineral; (C) ravinas decorrentes do fluxo pluvial canalizado. Fonte: acervo das autoras (12/2012).

uma estrutura paisagística constituída por planícies inundáveis que se alojam em fundos de vale pouco aprofundados (0 a 5 metros), escavados nos baixos platôs e tabuleiros por igarapés de água clara. O regime hidrológico é controlado pela sazonalidade pluviométrica. A cobertura vegetal reflete as características mesológicas, sobretudo as peculiaridades do meio físico e edáfico. São as florestas aluviais com Tachigalia sp., Symphonia sp., Mauritia sp., Euterpe sp., etc, que se desenvolvem sobre solos hidromórficos arenosos e argilosos.

Os componentes florísticos e faunísticos são utilizados como recursos extrativistas. Entretanto, este geossistema demarca áreas de baixa ocupação antrópica, o que lhe garante uma dinâmica progressiva, mantendo-se o potencial ecológico por sedimentação aluvial e gravitacional. Neste caso, encontramse como geofácies: a Planície aluvial com Euterpe sp. e a Planície aluvial com Mauritia sp. São geofácies em equilíbrio dinâmico, onde a vegetação é bem conservada e a intervenção humana é limitada.

Os setores degradados são decorrentes da construção de estradas e pontes, da implantação de balneários, do acúmulo de resíduos sólidos em função de atividades agrícolas ou urbanas e do desaparecimento de nascentes devido a mudanças na cobertura vegetal ou a uso inadequado do lençol freático. Corresponde a esta situação o geofácies: planície aluvial com mata degradada por alagamento prolongado ou por represamento de igarapés. Tratase de uma unidade com dinâmica progressiva em virtude da manutenção da vegetação florestal embora antropizada. Os geótopos são: canal assoreado por depósito de cascalho, canal assoreado por depósito arenoso, superfície lodosa por acúmulo de matéria orgânica vegetal e superfície aterrada e construída para lazer, circulação ou moradia (Figuras 9 e 10). 


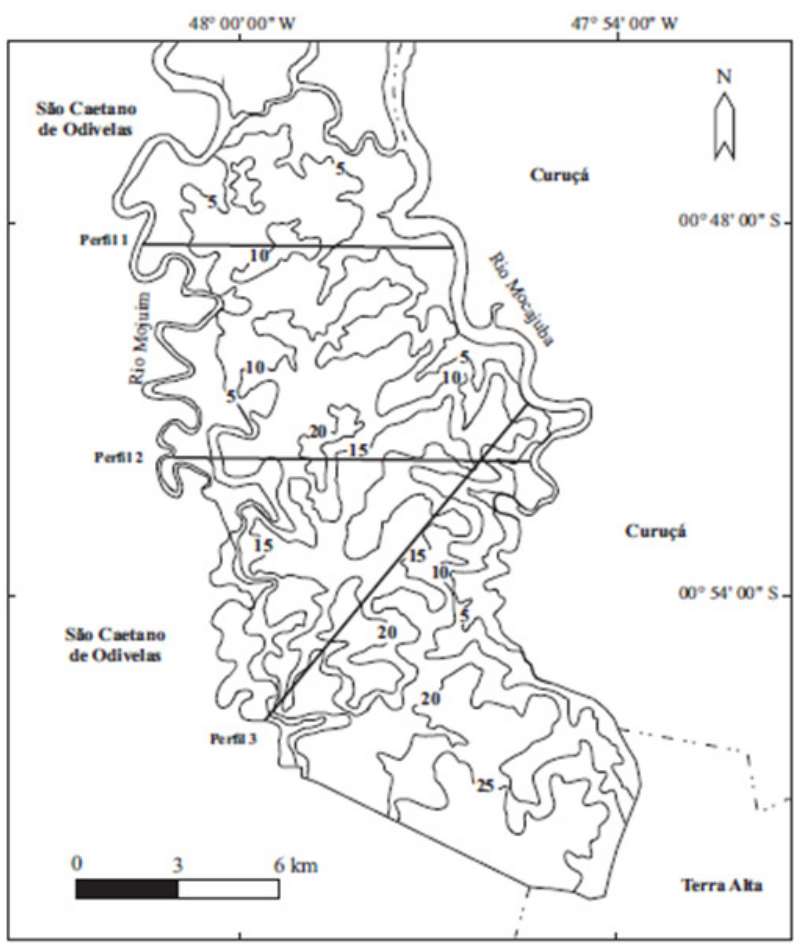

Figura 9: Mapa topográfico do município de São João da Ponta e localização dos transectos 1, 2 e 3. Fonte: elaborado pelas autoras.
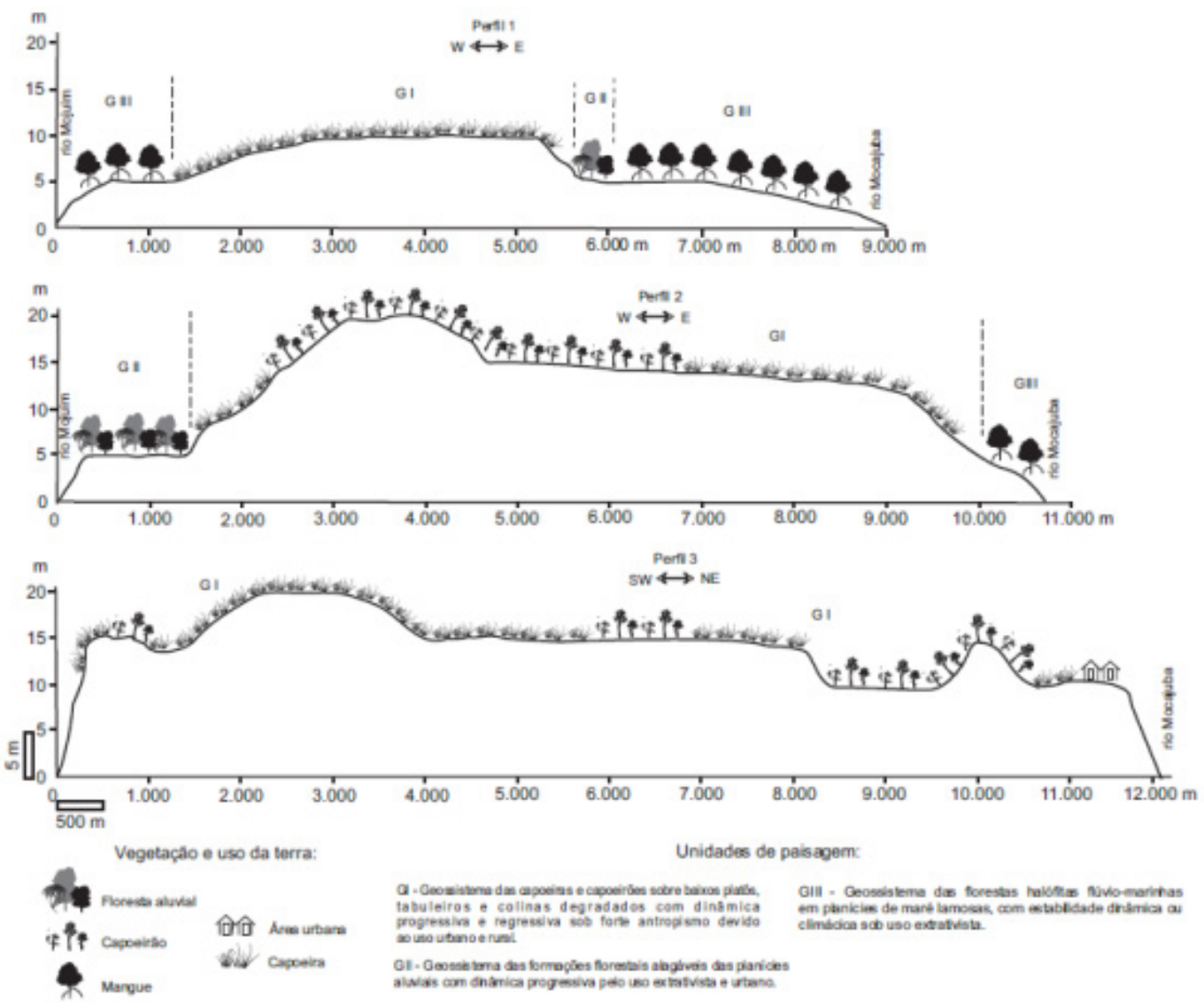

Figura 10: Distribuição dos geossistemas ao longo dos transectos topográficos 1, 2 e 3.

Fonte: elaborado pelas autoras. 


\section{CONSIDERAÇÕES FINAIS}

Do ponto de vista geográfico, o município de São João da Ponta situa-se numa porção recuada da costa nordeste paraense, sob a influência de dois importantes estuários: o Mojuim e o Mocajuba, que estabelecem, em parte, os limites municipais a oeste e leste. Esta posição geográfica é responsável por características peculiares, notadamente relacionadas à distribuição das formas de relevo e ao nível de inundação por maré, mas também ao acesso por rodovias estaduais e ao uso e ocupação da terra.

Trata-se de uma área significativa porque congrega várias dimensões territoriais: o poder político exercido pela prefeitura, os movimentos sociais extrativistas através da Associação Mocajuim, a área urbana com oferta de serviços básicos e as atividades pesqueiras de médio e pequeno porte. Porém, ao mesmo tempo, as dimensões físicas traduzidas pelas diferenças topográficas, pela hidrodinâmica e pelos fenômenos de erosão e de sedimentação, definem um arcabouço geomorfológico que dá sentido às atividades sócio-econômicas ou de uso da terra. Diante disso, a relação dos fatores físicos, biológicos e antrópicos forma conjuntos sistêmicos, abordados, neste trabalho, sob o aspecto fisionômico, ecológico e dinâmico, conforme os pressupostos da ciência da paisagem, preconizada pelo geógrafo francês Georges Bertrand.

A metodologia adotada, neste campo de estudo, revela os atributos que constituem as formas de relevo, as peculiaridades da cobertura vegetal, da hidrodinâmica flúvio-marinha e do uso da terra, cooperando simultaneamente para a identificação e classificação de unidades paisagísticas em três níveis de grandeza têmporo-espaciais.

Os geossistemas são unidades de $4 .^{a}$ grandeza, mapeadas em escala média e classificadas de acordo com as tipologias fisionômica e ecológica e dinâmica: Geossistema das capoeiras e capoeirões sobre baixos platôs, tabuleiros e colinas degradados com dinâmica progressiva e regressiva sob forte antropismo devido ao uso urbano e rural (GI); Geossistema das formações florestais alagáveis das planícies aluviais com dinâmica progressiva pelo uso extrativista e urbano (GII); e Geossistema das florestas halófitas flúvio-marinhas em planícies de maré lamosas, com estabilidade dinâmica ou climácica sob uso extrativista (GIII).

Cada geossistema subdivide-se em unidades de grandeza menores, geofácies e geótopos, que sintetizam arranjos espaciais mais localizados, nos quais são ressaltadas as combinações entre o quadro ecológico e a composição florística.

\section{REFERÊNCIAS BIBLIOGRÁFICAS}

BARBOSA, G. V.; PINTO, M. N. Geomorfologia da Folha SA.23 São Luís e parte da Folha SA.24 Fortaleza. In: BRASIL. DEPARTAMENTO NACIONAL DE PRODUÇÃO MINERAL. Projeto RADAM. Folha SA.23 São Luís e parte da Folha SA.24 Fortaleza; geologia, geomorfologia, solos, vegetação e uso potencial da terra. Rio de Janeiro: Ministério das Minas e Energia, Departamento Nacional de Produção Mineral, 1973. (Levantamento de Recursos Naturais, 3).

BERTRAND, G. Paisagem e Geografia Física Global. Esboço metodológico. Caderno de Ciências da Terra, n. 13, p. 1-27, 1971.

IBGE - Instituto Brasileiro de Geografia e Estatística. Divisão do Brasil em Mesorregiões e Microrregiões Geográficas. Rio de Janeiro: Fundação Instituto Brasileiro de Geografia e Estatística, Diretoria de Geociências, Departamento de Geografia, 1990.

IBGE - Instituto Brasileiro de Geografia e Estatística. Manual Técnico da Vegetação Brasileira. Rio de Janeiro: Fundação Instituto Brasileiro de Geografia e Estatística, Departamento de Recursos Naturais e Estudos Ambientais,1991. (Série Manuais Técnicos de Geociências, 1).

MARINHA DO BRASIL. Diretoria de Hidrografia e Navegação. Previsões de Marés. Disponível em: http:// www.mar.mil.br. Acesso em: 21 jan. 2015.

RODRIGUEZ, J. M. M.; SILVA, E. V.; CAVALCANTI, A. P. B. Geoecologia das Paisagens: uma visão geossistêmica da análise ambiental. 3. ed. Fortaleza: Edições UFC, 2010.

SIOLI, H. Amazônia. Fundamentos de ecologia da maior Região de Florestas Tropicais. Petrópolis: Vozes, 1990. 
Correspondência das autoras:

Carmena Ferreira de França

e-mail: carmena@ufpa.br

Marcia Aparecida da Silva Pimentel

e-mail: mapimentel@ufpa.br

Silvia Caroline Ribeiro Neves

caroline2010ribeiro@gmail.com

Artigo recebido em: 19/05/2015

Revisado pelas autoras em: 28/03/2016

Aceito para publicação em: 29/03/2016 